\title{
Simulation and Optimization of Dynamic Fracture Parameters for an Inverted Square Nine-Spot Well Pattern in Tight Fractured Oil Reservoirs
}

\author{
Le Jiang, ${ }^{1}$ Peng Gao, ${ }^{2}$ Jie Liu, ${ }^{1}$ Yunbin Xiong, ${ }^{2}$ Jing Jiang, ${ }^{3}$ Ruizhong Jia, ${ }^{2}$ Zhongchao Li, $^{2}$ \\ and Pengcheng Liu ${ }^{1}{ }^{1}$ \\ ${ }^{1}$ School of Energy Resources, China University of Geosciences, Beijing 100083, China \\ ${ }^{2}$ Research Institute of Petroleum Exploration and Development of Zhongyuan Oilfields, SINOPEC, Puyang 457100, China \\ ${ }^{3}$ Tianjin Branch of CNOOC (China) Co., Ltd., Tianjin 300000, China \\ Correspondence should be addressed to Pengcheng Liu; liupengcheng8883@sohu.com
}

Received 4 August 2020; Revised 19 August 2020; Accepted 7 September 2020; Published 22 September 2020

Academic Editor: Amgad Salama

Copyright (C) 2020 Le Jiang et al. This is an open access article distributed under the Creative Commons Attribution License, which permits unrestricted use, distribution, and reproduction in any medium, provided the original work is properly cited.

\begin{abstract}
Dynamic fractures are a geological attribute of water flooding development in tight fractured oil reservoirs. However, previous studies have mainly focused on the opening mechanism of dynamic fractures and the influence of dynamic fractures on development. Few attempts have been made to investigate the optimization of the dynamic fracture parameter. In this study, the inverted square nine-spot well pattern model is established by taking fractured reservoir's heterogeneity and its threshold pressure gradients into account. This simulation model optimizes the various parameters in a tight fractured oil reservoir with dynamic fractures, that is, the intersection angle between the dynamic fractures and the well array, the number of dynamic fractures, the penetration ratio, and the conductivity of the oil well's hydraulic fractures. The results of this optimization are used to investigate the oil displacement mechanism of dynamic fractures and to discuss a mechanism to enhance oil recovery using an inverted square nine-spot well pattern. The simulation results indicate that a $45^{\circ}$ intersection angle can effectively restrain the increase in the water cut. A single dynamic fracture can effectively control the displacement direction of the injected water and improve the oil displacement efficiency. Moreover, the optimal penetration ratio and the conductivity of the hydraulic fracture are 0.6 and $40 \mathrm{D}-\mathrm{cm}$, respectively.
\end{abstract}

\section{Introduction}

Dynamic fractures are a geological phenomenon produced during the long-time water flooding process in tight fractured oil reservoirs. Dynamic fractures, controlled by the current stress field, constantly extend toward the direction of the maximum horizontal principal stress with the rise of the injected water volume and bottom hole pressure. Water flooding dynamic fractures are the main flow channel in tight fractured oil reservoirs. Dynamic fractures can improve the percolation capacity of tight fractured oil reservoirs and directly enhance the productivity of the oil well. Dynamic fractures play a positive role in establishing an effective displacement system for an injection production well pattern $[1,2]$. However, the dynamic fractures change the water flooding percolation characteristics, significantly worsen the reservoir's heterogeneity, and seriously affect the swept volume during the water flooding process [3].

A tight fractured oil reservoir is defined as having a reservoir matrix permeability of $\leq 0.1 \mathrm{mD}$. At present, fractured reservoir's geological properties such as permeability and heterogeneity have been studied $[4,5]$. In addition, enhanced oil recovery technologies such as gas injection, water flooding, water huff-n-puff, chemical flooding, and hydraulic fracturing have also been studied [5-19]. The studies conducted on hydraulic fractures have mainly focused on fluid flow within the hydraulic fractures and pressure behaviors of the fracturing process [20-24].

Water flooding is a common method of enhancing oil recovery from tight fractured oil reservoirs. Long-time 


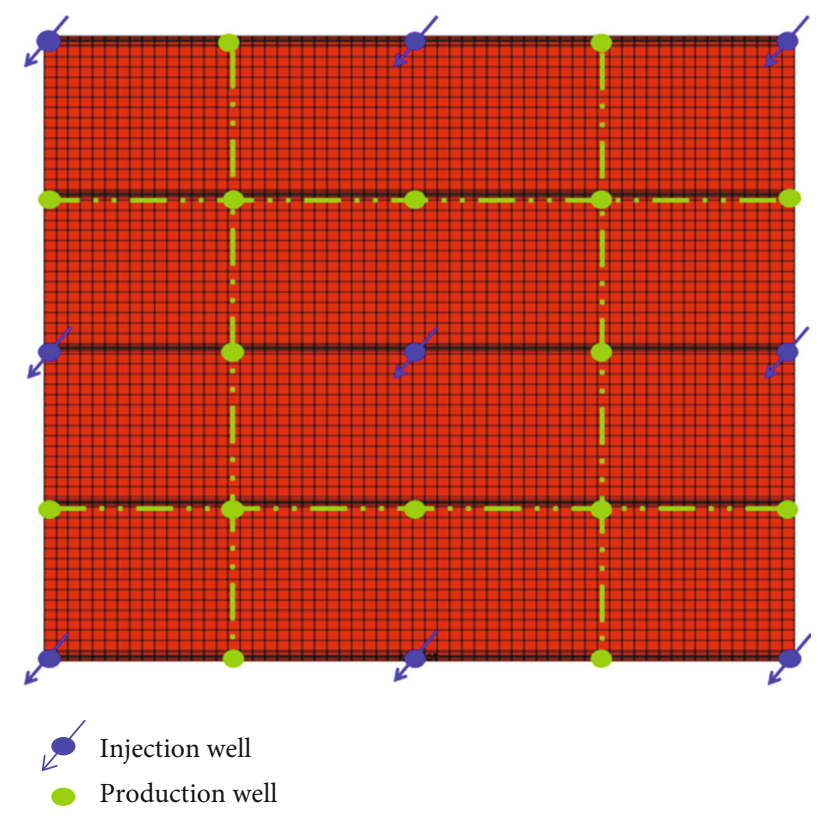

FIGURE 1: Schematic of the grid model and well pattern.

injection at a high pressure is necessary to improve oil production. The injected water leads to a high pressure near the wellbore area of the injection well. The originally closed natural fractures are reactivated when the bottom hole pressure of the injection well exceeds the fracture extension pressure, or the reservoir generates new fractures when the bottom hole pressure of the injection well exceeds the rock breakdown pressure. These new fractures are defined as water flooding dynamic fractures, which are similar to the formation mechanism of the "growth fractures of water flooding" proposed by some researchers [25, 26].

There are two main opinions about the opening mechanism of the water flooding dynamic fractures. One is that the opening of dynamic fractures is controlled by both the current horizontal principal stress and the natural fractures. The opening sequence of the water flooding dynamic fractures depends on the intersection angle between the natural fracture direction and the current maximum horizontal principal stress direction. The opening pressure of natural fracture decreases as the intersection angle decreases. The injection water flows through the natural fractures along the maximum horizontal principal stress direction. The natural fractures successively open in other directions with increasing injection pressure. Reservoirs experience single-directional or multidirectional fracture flooding $[27,28]$. The other opinion is that the opening of the water flooding dynamic fractures mainly depends on the relative magnitude of the current horizontal stress in the connection direction of the injection production wells. Dynamic fractures are generated in the connection direction of the injection production well when the bottom hole pressure of the injection well is greater than the current horizontal stress in the connection direction of the injection production well. Oil wells with dynamic fractures experience fracture flooding [29].
For the past few years, many researchers modeling fractures in tight fractured oil reservoirs have focused on applications of natural fractures models and hydraulic fractures models [30-33]. Furthermore, the modeling of dynamic fractures has mainly focused on ultralow-permeability reservoirs [34]. Based on the numerical simulations, it is concluded that the negative effects of dynamic fractures can be minimized when a nine-spot well pattern is adopted [35].

In summary, previous studies have mainly focused on the opening mechanism of dynamic fractures and the influence of dynamic fractures on oilfield development. However, few studies have focused on optimizing the dynamic fracture parameters. In this paper, the inverted square nine-spot well pattern model is established. This simulation model is used to optimize two dynamic fracture parameters: the intersection angle between the dynamic fracture and the well array and the number of dynamic fractures. Based on these optimized dynamic fracture parameters, the penetration ratio and conductivity of the oil well's hydraulic fractures are optimized. The tight fractured oil reservoir's heterogeneity and threshold pressure gradient are fully considered in the model. The simulation results provide the optimal well pattern arrangement and hydraulic fracturing scheme for water flooding development in tight fractured oil reservoirs.

\section{Reservoir Modeling}

2.1. Well Pattern and Grid Model. Figure 1 shows the grid model used in the tight fractured oil reservoirs simulation. The blue points are injection wells; the green points are production wells. The top layer depth of the reservoir is $1600 \mathrm{~m}$, the grid's dimensions are $61 \times 61 \times 3$, and the volume of the grid is $20 \times 20 \times 5 \mathrm{~m}^{3}$. The well array spacing and the well spacing are both $300 \mathrm{~m}$.

The local grid refinement (LGR) method was used to build the fracture model. According the principle of equivalent conductivity, the dynamic fracture width was $4 \mathrm{~m}$, the fracture permeability was $100 \mathrm{mD}$, and the height of the fracture was equal to the thickness of the reservoir model.

2.2. Simulation Model. Typical tight fractured oil reservoirs data for the Zhongyuan oilfield XX block (China) was selected to build the numerical simulation model. The natural fractures were distributed in the direction of the current maximum horizontal principal stress in the numerical simulation model. And these natural fractures are closed due to the effect of the formation pressure. The black oil model in Eclipse software was used to simulate the water flooding process. The parameters of the dynamic fracture and the hydraulic fracture were optimized. The key reservoir properties are listed in Table 1. As can be seen from Figure 2, the matrix phase permeability curve was obtained from the phase permeability data of Zhongyuan oilfield XX block (China); the fracture phase permeability curve indicates the oil-water two-phase seepage in the fracture.

The natural fractures greatly enhance the formation's heterogeneity in the fractured reservoir. So the $Y$-direction permeability and $Z$-direction permeability were set as 
TABLE 1: Key simulation parameters used in the model.

\begin{tabular}{|c|c|c|c|}
\hline Item & Value & Item & Value \\
\hline Oil-water interface $(\mathrm{m})$ & 2100 & Threshold pressure gradient $(\mathrm{MPa} / \mathrm{m})$ & 0.012 \\
\hline Initial formation pressure (MPa) & 20.5 & Matrix porosity $(\%)$ & 11 \\
\hline$X$-direction permeability $(\mathrm{mD})$ & 0.1 & Fracture porosity (\%) & 20 \\
\hline Oil viscosity $(\mathrm{mPa} \cdot \mathrm{s})$ & 0.97 & Rock compression coefficient $\left(\mathrm{MPa}^{-1}\right)$ & $3.2 \times 10^{-4}$ \\
\hline Oil density $\left(\mathrm{kg} / \mathrm{m}^{3}\right)$ & 879.5 & Water compression coefficient $\left(\mathrm{MPa}^{-1}\right)$ & $5 \times 10^{-4}$ \\
\hline
\end{tabular}

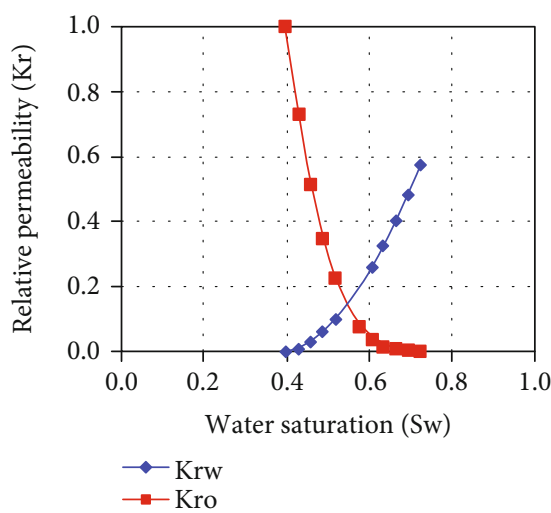

(a)

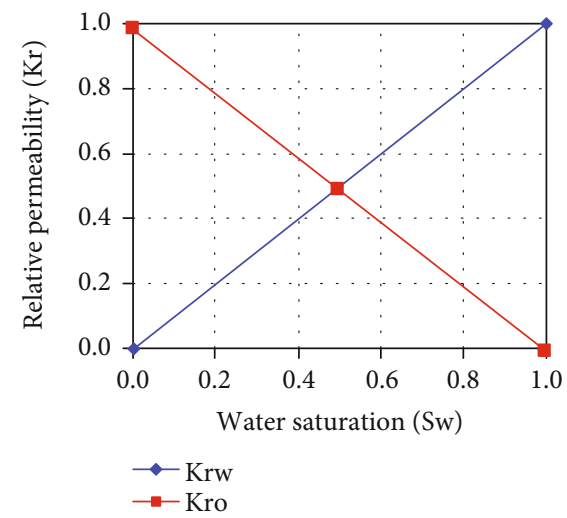

(b)

FIGURE 2: The phase-permeability curves of the matrix and fracture. (a) Matrix phase permeability curve and (b) fracture phase permeability curve.

TABLE 2: Formation pressure data.

\begin{tabular}{lccc}
\hline Item & Value $(\mathrm{MPa})$ & Item & Value $(\mathrm{MPa})$ \\
\hline Minimum horizontal principal stress & 22 & Open pressure of second fracture & 24.1 \\
Maximum horizontal principal stress & 25 & Difference between max stress and min stress & 3 \\
\hline
\end{tabular}

$0.025 \mathrm{mD}$ and $0.0025 \mathrm{mD}$, which are one-fourth and onefortieth the $X$-direction permeability, respectively. The oil wells in the dynamic fractures appear to be fracturedflooded after a certain water flooding period [10], so the oil wells were converted to water injection wells when the water cut reached $90 \%$.

The opening of the dynamic fractures is related to the injection well's bottom hole pressure and the current horizontal stress. The natural fractures are closed when the bottom hole pressure of the injection well is less than the current minimum horizontal principal stress. This type of model is called a no fracture model. The originally closed natural fractures are reactivated in the direction of the current maximum horizontal principal stress when the injection well's bottom hole pressure is between the current minimum horizontal principal stress and the opening pressure of the second direction dynamic fracture. This type of model is called single fracture model. The reservoir generates second direction dynamic fractures when the bottom hole pressure of the injection well is greater than the second direction fractures' opening pressure. The second dynamic fracture appears along the connection orientation of the injectionproduction well [29]. This type of model is called double frac- ture model. The formation pressure data are presented in Table 2 .

\section{Results and Discussion}

3.1. Intersection Angle between the Dynamic Fracture and the Well Array. The water flooding dynamic fractures propagate along originally natural fractures' direction. There is an intersection angle between the water flooding dynamic fracture direction and the well array direction, which affects the displacement of the injection water. In this study, the intersection angle was set to $0^{\circ}, 22.5^{\circ}$, and $45^{\circ}$. Oil well hydraulic fracturing is essential to the water flooding development of tight fractured oil reservoirs. And the hydraulic fractures also propagate along the current maximum horizontal principal stress direction. According to technical opinions, the effect of water flooding development is significant when an oil well's hydraulic fractures are connected. According to the principle of equivalent conductivity, the hydraulic fracture width was $4 \mathrm{~m}$, the fracture permeability was $100 \mathrm{mD}$, and the height of the fracture was equal to the thickness of the reservoir model. Therefore, the oil well hydraulic fractures were connected in the model. 


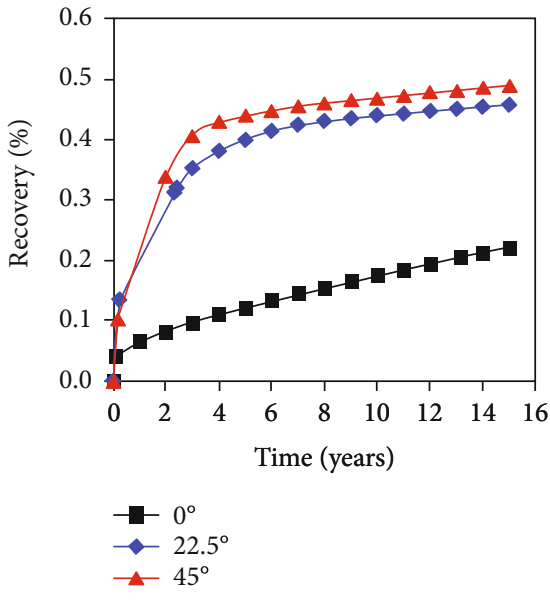

(a)

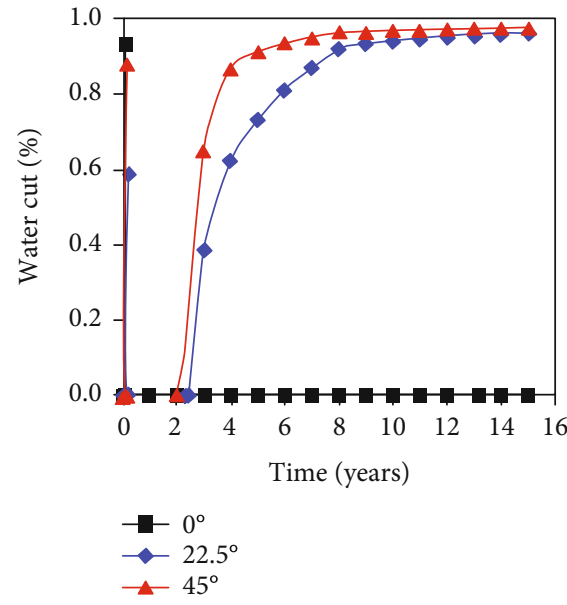

(b)

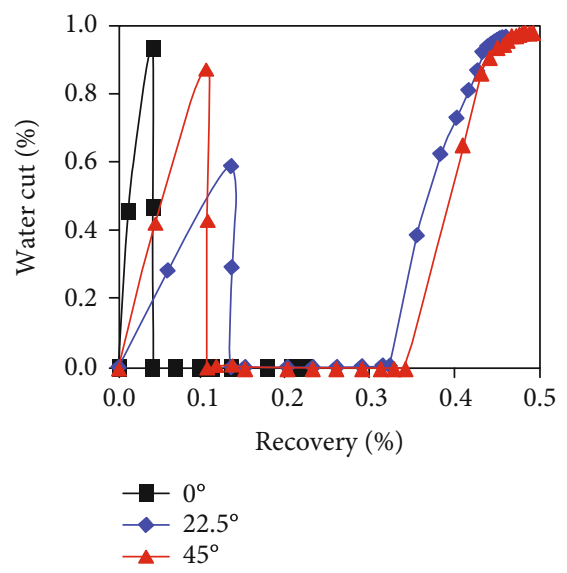

(c)

Figure 3: The production curves of the different angle models. (a) Recovery versus time, (b) water cut versus time, and (c) water cut versus recovery.

The single fracture model was selected for comparison and analysis. Figures 3 and 4 show the production curves and the remaining oil distribution of the different angle models, respectively.

From Figures 3 and 4, the production curves and the change in the remaining oil distribution can be comparatively analyzed. The recovery degree and the water cut continuously increase as the angle increases. The recovery degree and the water cut are the largest when the intersection angle is $45^{\circ}$. After a certain water flooding period, the oil wells in the dynamic fractures appear to be fractured-flooded lead to rapidly increasing of water cut. Then, the water cut declines to zero after the oil wells are converted to water injection wells. Under the same water cut conditions, the recovery degree is higher when the angle is $45^{\circ}$. Therefore, the effect on the development is significant when the intersection angle is $45^{\circ}$.

The double fracture model was also analyzed. The comparative results for different angles are presented in Table 3. From Table 3, the production data were compared. The recovery degree and the water cut are the largest when the intersection angle between the first dynamic fracture direction and the well array's direction is $45^{\circ}$. Under the same water cut conditions, the recovery degree is higher when the angle is $45^{\circ}$. Therefore, the effect on the development is significant when the intersection angle is $45^{\circ}$.

By comparing the production curves and the remaining oil distributions for the different intersection angles, the swept volume of the water flooding mechanism of dynamic fracture expansion mainly includes the following aspects.

(1) The water flooding mode changes to linear injection and lateral displacement after the oil well is converted to an injection well, and the well pattern mode changes to a large well spacing and a small well array spacing

(2) The lateral displacement is approximately uniform. The uniform displacement significantly increases recovery

(3) The well array spacing is the smallest when the intersection angle is $22.5^{\circ}$, and the well interference is 

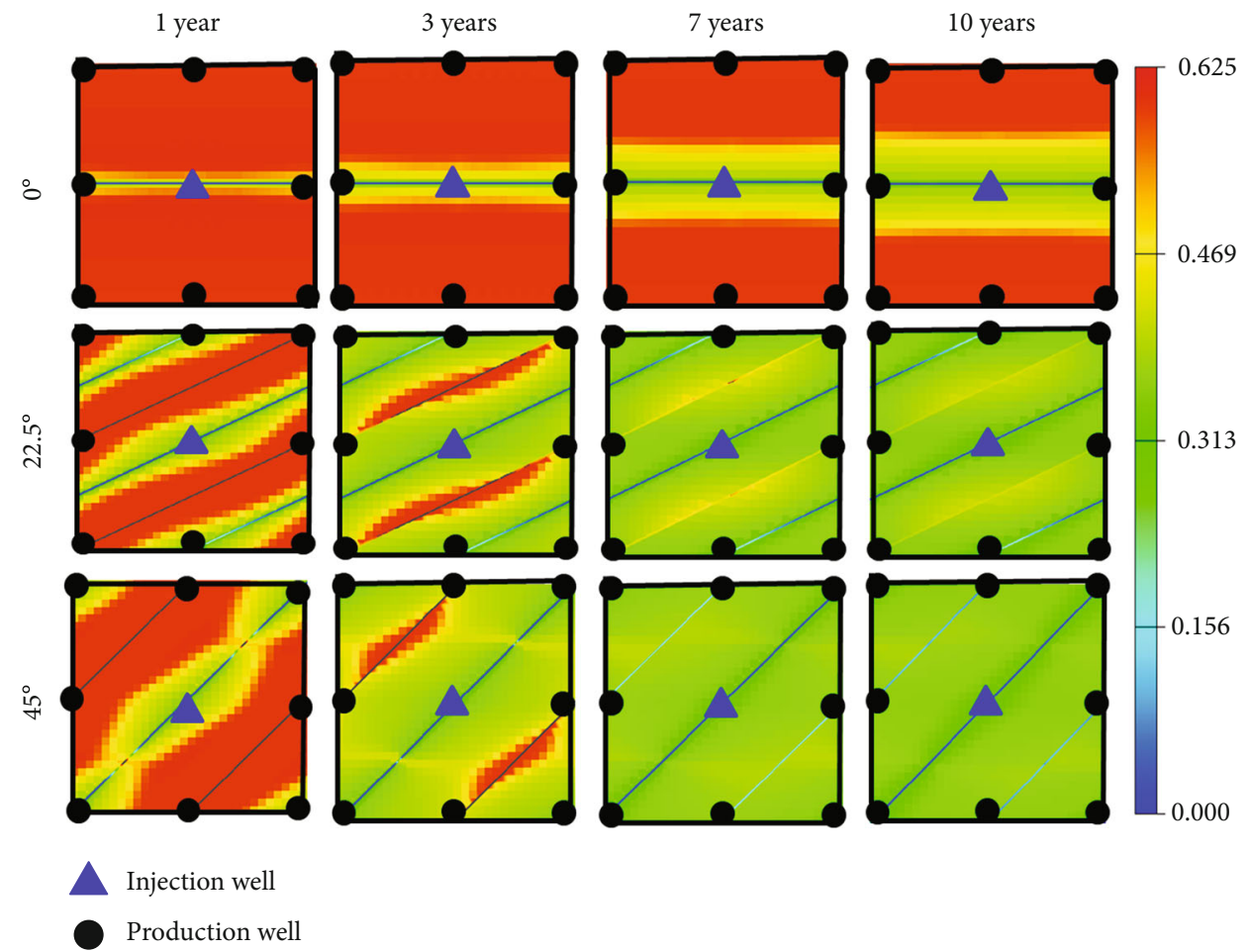

FIgURE 4: Planar distribution of the remaining oil saturation at different intersection angles and times.

TABLE 3: Comparison of the results for the different angles.

\begin{tabular}{lccc}
\hline Items & Recovery & Water cut & $\begin{array}{c}\text { Recovery at the same } \\
\text { water cut }\end{array}$ \\
\hline $\begin{array}{l}\text { Relative } \\
\text { size }\end{array}$ & $45^{\circ}>22.5^{\circ}>0^{\circ}$ & $45^{\circ}>22.5^{\circ}>0^{\circ}$ & $45^{\circ}>22.5^{\circ}>0^{\circ}$ \\
\hline
\end{tabular}

significant. The small well array spacing results in the rapid spread of the water flooding front into the oil well's hydraulic fractures, and the oil well experiences fracture flooding

(4) The effect on the development is significant when the intersection angle between the dynamic fracture direction and the well array direction is $45^{\circ}$

3.2. Number of Dynamic Fractures. In this paper, we established no fracture, single fracture, and double fracture models. The intersection angle between the dynamic fracture direction and the well array's direction was set to $45^{\circ}$, and the oil well's hydraulic fractures were connected. Figures 5 and 6 display the simulation results, respectively, for different numbers of dynamic fractures.

Figures 5 and 6 were used to compare the production curves and the changes in the remaining oil distribution for different numbers of fractures. The recovery degree and the water cut were both relatively high when the reservoir generates double-direction dynamic fractures. After a certain water flooding period, the oil wells in the dynamic fractures appear to be fractured-flooded lead to rapidly increasing of water cut. Then, the water cut declines to zero after the oil wells are converted to water injection wells for the single fracture model. The double-direction dynamic fractures are likely to lead to the side-oil wells and oil wells in the dynamic fractures being fracture-flooded. So the water cut does not decline after the oil wells in the dynamic fractures are converted to water injection wells for the double fracture model. The double-direction dynamic fractures are likely to lead to the side wells being fracture-flooded. Under the same water cut conditions, the recovery degree is relatively high when the reservoir generates single-direction dynamic fractures. Therefore, the effect on the development is significant when the reservoir generates single-direction dynamic fractures.

A better development method of enhancing oil recovery is to reduce the speed of the injected water to avoid generating double-direction fractures. This method can effectively reduce the invalid circulation of the injected water and the flooded degree of the side well.

\subsection{Penetration Ratio of the Oil Well's Hydraulic Fractures.} The contact area between the reservoir and a hydraulic fracture increases as the length of the hydraulic fracture increases. The effect on the reservoir development is the best when the hydraulic fractures are connected. However, the fracturing cost increases as the length of the hydraulic fracture increases. The economic benefit is likely to decrease when the oil well's hydraulic fractures are connected. Therefore, it is necessary to compare the reservoir's development status for different hydraulic fracture lengths. In this study, we determined the optimal penetration ratio by optimizing the hydraulic fracture length. The penetration ratio is defined 


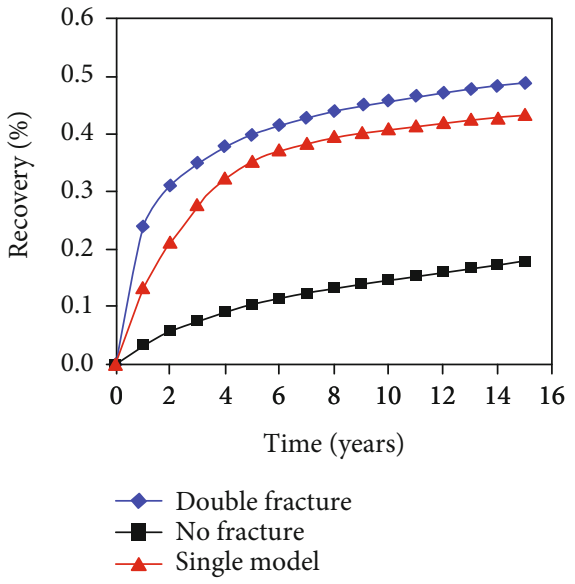

(a)

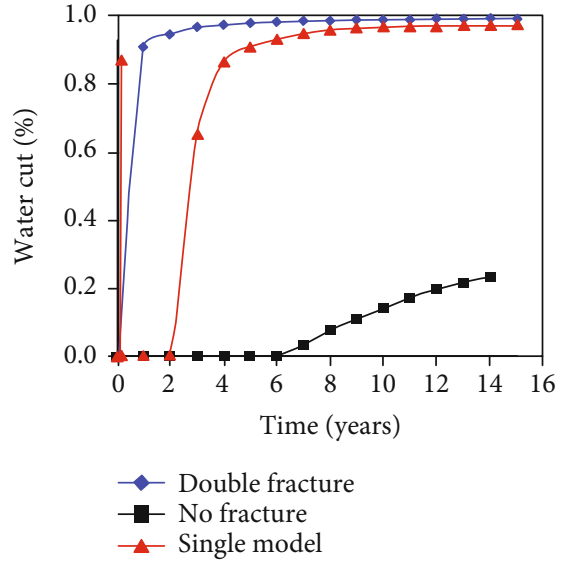

(b)

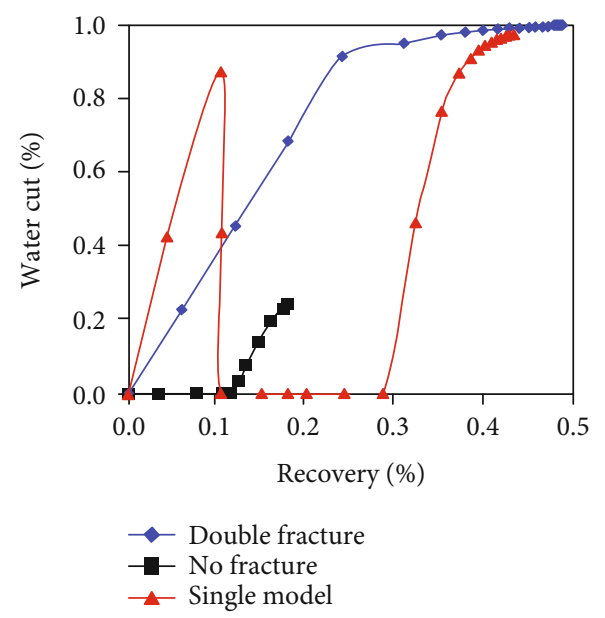

(c)

Figure 5: The production curves for different numbers of dynamic fracture. (a) Recovery versus time, (b) water cut versus time, and (c) water cut versus recovery.

as the ratio of the fracture half-length to the half-well spacing in the hydraulic fracture direction.

To study the optimal penetration ratio of a hydraulic fracture, seven penetration ratios were used in each simulation model: $0.2,0.4,0.5,0.6,0.7,0.8$, and 1.0. The intersection angle between the current maximum horizontal principal stress direction and the well array direction was set as $45^{\circ}$. Then, the penetration ratio of the oil well's hydraulic fracture was optimized.

According to the numerical simulation result for a 15year period, the daily oil production and the cumulative oil production increase as the penetration ratio increases, but there is no obvious turning point. Thus, the slope of the cumulative oil production curve was selected as the comparison parameter, as shown in Figure 7.

From Figure 7, the slope goes down as the penetration ratio increases. There is an inflection point. When the penetration ratio increases to 0.6 , the rate at which the slope decreases slows down, and a turning point occurs. If the penetration ratio is greater than 0.6 , the economic benefit of increasing the hydraulic fracture length is less than the fracturing cost.
In short, the optimal penetration ratio of oil well hydraulic fractures is 0.6 . It is unnecessary that the hydraulic fracture length be as long as possible. A suitable penetration ratio for the oil well hydraulic fracture controls the fracturing cost and improves the economic benefits.

3.4. Conductivity of Oil Well Hydraulic Fractures. The conductivity refers to the fluid flow capacity of a hydraulic fracture. According to previous studies, the conductivity is defined as the product of the permeability and the fracture width [36]. The conductivity of the hydraulic fracture affects the development by affecting the fluid percolation properties within the oil well's hydraulic fractures. The intersection angle between the current maximum horizontal principal stress direction and the well array's direction was set as $45^{\circ}$, and the penetration ratio of the oil well's hydraulic fracture was set as 0.6 . Then, the conductivity of the oil well's hydraulic fractures was optimized.

Based on the simulation results for a 15 -year period, the daily oil production can be increased by diverting the capacity of the oil well's hydraulic fractures before the oil well is converted to an injection well. Therefore, the average daily 


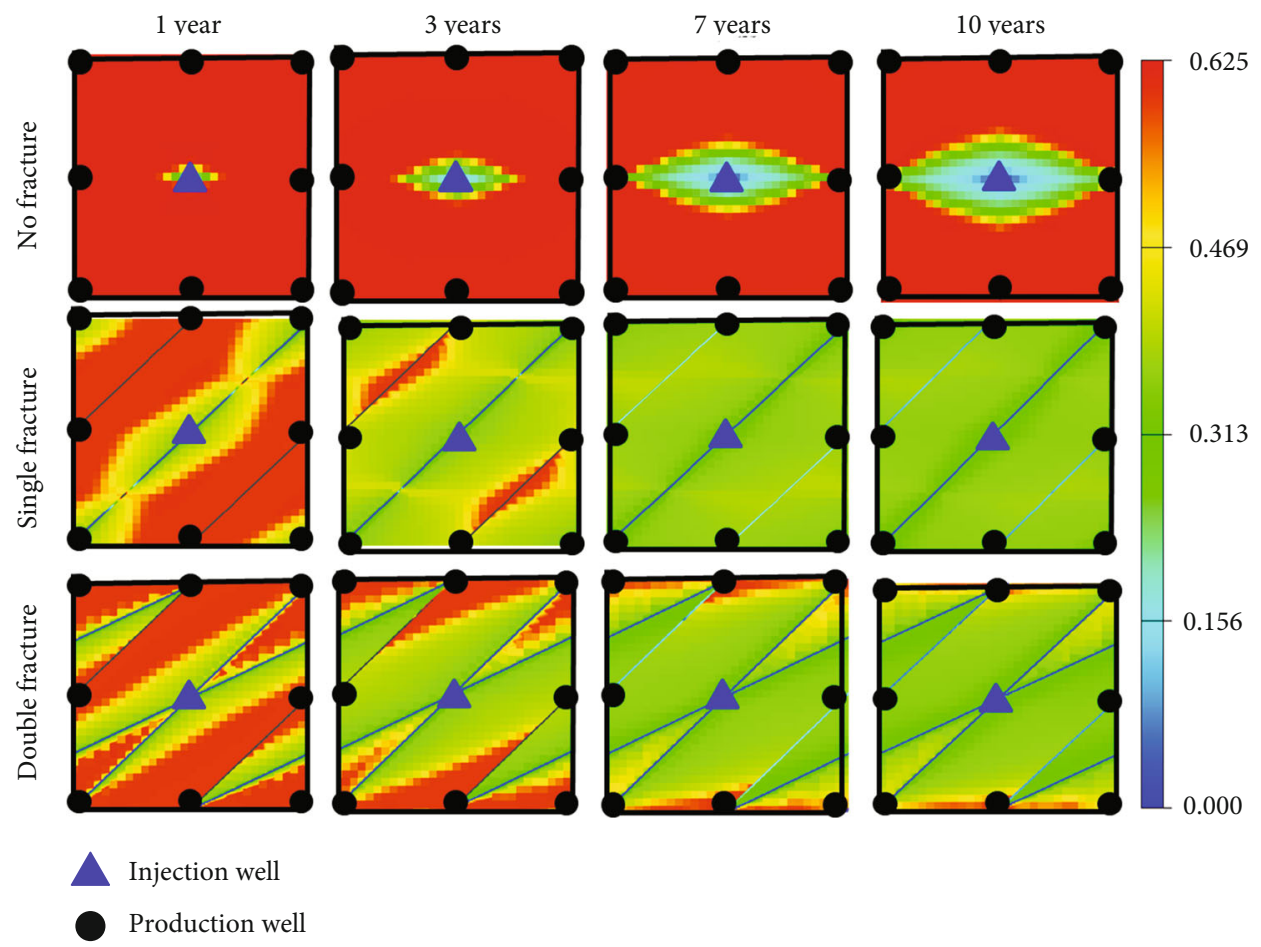

Figure 6: Planar distribution of the remaining oil saturation for different numbers of dynamic fractures and different times.

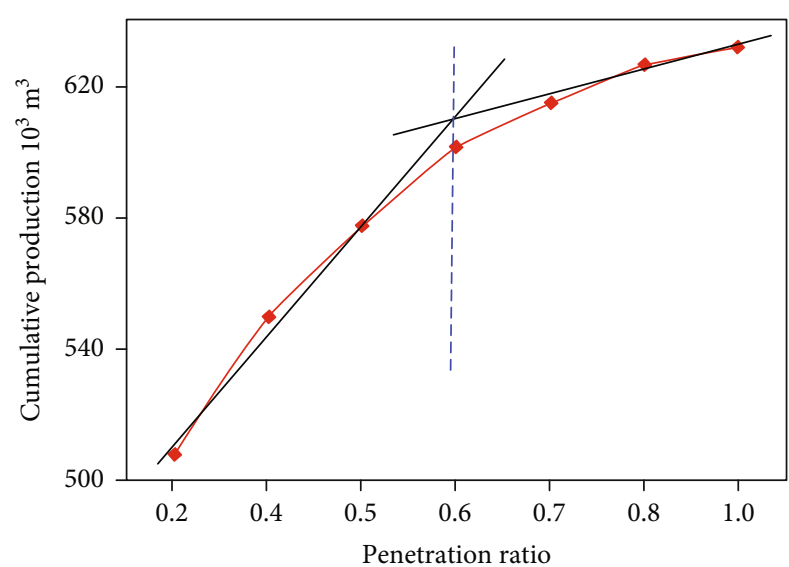

(a)

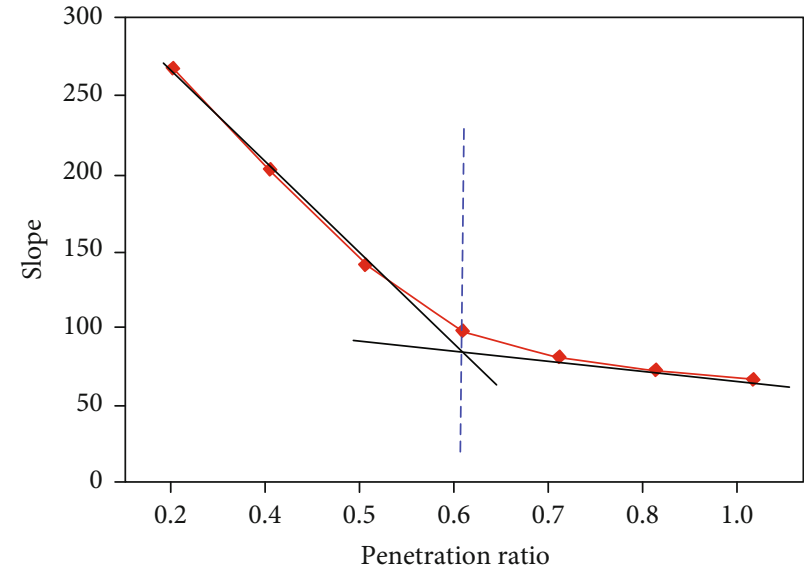

(b)

FIgURE 7: Cumulative oil production curves for different hydraulic fracture penetration ratios. (a) Cumulative oil production versus penetration ratio, and (b) slope of the cumulative oil production curve versus penetration ratio.

oil production before the oil well is converted to an injection well was used as the comparison parameter. Figure 8 shows the curve of the inducting capacity versus the average daily oil production.

From Figure 8, the rate at which the average daily oil production increases begins to decrease when the conductivity of hydraulic fracture reaches about $40 \mathrm{D}$ - $\mathrm{cm}$. There is an inflection point. The economic benefits begin to decrease when the conductivity of the hydraulic fracture is greater than $40 \mathrm{D}$ $\mathrm{cm}$.

In a word, the optimal conductivity of an oil well's hydraulic fracture is $40 \mathrm{D}-\mathrm{cm}$. It is unnecessary that the con- ductivity of the oil well's hydraulic fracture is as high as possible. A suitable conductivity of an oil well's hydraulic fracture effectively controls the fracturing cost and improves the economic benefits.

\section{Conclusions}

(1) The controlling fracture and fracture matching well pattern modes are the best for avoiding oil well fracture flooding. The linear injection and lateral displacement are the best adjustment modes for water flooding development of tight fractured oil reservoirs. 


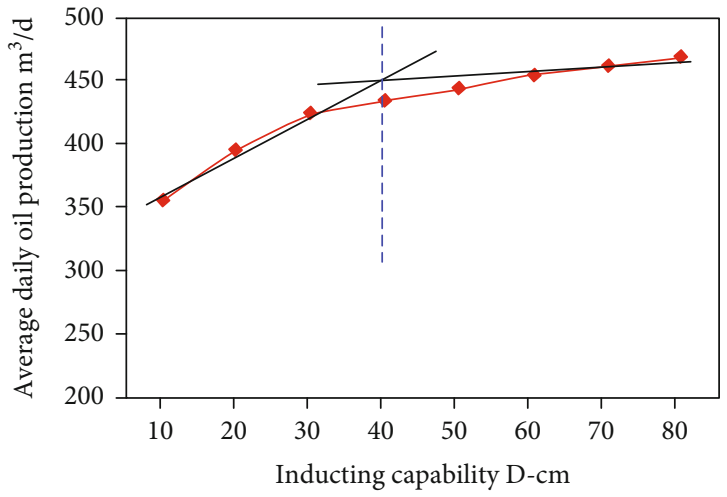

FIgURE 8: Average daily oil production versus conductivity.

The displacement mode effectively improves the displacement efficiency of the lateral plane of the reservoir's matrix

(2) The inverted square nine-point well pattern has the effect on the best development when the intersection angle between the dynamic fracture direction and the well array direction is $45^{\circ}$. An intersection angle of $45^{\circ}$ effectively controls the increase in the water cut. The fracture matching well pattern mode controls the side well fracture flooding

(3) The inverted square nine-spot well pattern provides the best development when the reservoir generates single-direction dynamic fractures. These fractures effectively control the displacement direction of the injected water. Furthermore, single-direction dynamic fractures effectively prevent the ineffective circulation of the injected water caused by the opening of the double-direction dynamic fractures

(4) It is unnecessary that the penetration ratio and the conductivity of the oil well's hydraulic fractures are as high as possible for tight fractured oil reservoirs. For the Zhongyuan tight fractured oil reservoirs, the optimal penetration ratio of the oil well's hydraulic fractures is 0.6 , and the best conductivity of the oil well's hydraulic fractures is around $40 \mathrm{D}-\mathrm{cm}$

\section{Data Availability}

The data used to support the findings of this study are intersection within the article.

\section{Conflicts of Interest}

The authors declare that there is no conflict of interests regarding the publication of this paper.

\section{Acknowledgments}

This research was financially supported by the Development of Zhongyuan Oilfields, SINOPEC Petroleum Exploration and Research Institute (No. 31300027-19-ZC0613-0014), and Science and Technology Special Funds of China (No. 2016ZX05015-002).

\section{References}

[1] L. Cheng, D. Wang, R. Cao, and R. Xia, "The influence of hydraulic fractures on oil recovery by water flooding processes in tight oil reservoirs: an experimental and numerical approach," Journal of Petroleum Science and Engineering, vol. 185, p. 106572, 2020.

[2] H. Wang, J. Guo, and L. Zhang, "A semi-analytical model for multilateral horizontal wells in low-permeability naturally fractured reservoirs," Journal of Petroleum Science and Engineering, vol. 149, pp. 564-578, 2017.

[3] Y. Wang, X. Song, C. Tian et al., "Dynamic fractures are an emerging new development geological attribute in waterflooding development of ultra-low permeability reservoirs," Petroleum Exploration and Development, vol. 42, no. 2, pp. 247-253, 2015.

[4] Y. Lu, S. Wei, Y. Xia, and Y. Jin, "Modeling of geomechanics and fluid flow in fractured shale reservoirs with deformable multi-continuum matrix," Journal of Petroleum Science and Engineering, vol. 196, p. 107576, 2021.

[5] M. G. Correia, C. Maschio, D. J. Schiozer, and M. S. . Santos, "Upscaling approach for meso-scale heterogeneities in naturally fractured carbonate reservoirs," Journal of Petroleum Science \& Engineering, vol. 115, pp. 90-101, 2014.

[6] F. A. Aljuboori, J. H. Lee, K. A. Elraies, and K. D. Stephen, "The effectiveness of low salinity waterflooding in naturally fractured reservoirs," Journal of Petroleum Science and Engineering, vol. 191, p. 107167, 2020.

[7] L. Wang and W. Yu, "Mechanistic simulation study of gas puff and huff process for Bakken tight oil fractured reservoir," Fuel, vol. 239, pp. 1179-1193, 2019.

[8] N. Liu, Z. Zhang, Y. Zou, X. Ma, and Y. Zhang, "Propagation law of hydraulic fractures during multi-staged horizontal well fracturing in a tight reservoir," Petroleum Exploration and Development, vol. 45, no. 6, pp. 1129-1138, 2018.

[9] J. Zhang, X. Zhang, Y. Ma, Y. Liu, and L. Zhang, "Performance evaluation and mechanism with different $\mathrm{CO}_{2}$ flooding modes in tight oil reservoir with fractures," Journal of Petroleum Science and Engineering, vol. 188, p. 106950, 2020.

[10] M. Ding, M. Gao, Y. Wang, Z. Qu, and X. Chen, "Experimental study on CO2-EOR in fractured reservoirs: influence of fracture density, miscibility and production scheme," Journal of Petroleum Science and Engineering, vol. 174, pp. 476-485, 2019.

[11] A. Bagherinezhad, R. Boozarjomehry Bozorgmehry, and M. R. Pishvaie, "Multi-criterion based well placement and control in the water-flooding of naturally fractured reservoir," Journal of Petroleum Science and Engineering, vol. 149, pp. 675-685, 2017.

[12] S. Liu, L. Zhang, K. Zhang, J. Zhou, H. He, and Z. Hou, “A simplified and efficient method for water flooding production index calculations in low permeable fractured reservoir," Journal of Energy Resources Technology, vol. 141, no. 11, pp. 1-31, 2019.

[13] H. Y. Jung, T. Onishi, and A. Datta-Gupta, "Numerical simulation of EOR from wettability alteration in tight fractured oil reservoirs with multiple hydraulic fractures," in SPE 191409, In: SPE Annual Technical Conference and Exhibition, pp. 122, Dallas, Texas, USA, September 2018. 
[14] P. Ø. Andersen, “A simplified modelling approach for petroleum recovery by spontaneous imbibition in naturally fractured reservoirs," Journal of Natural Gas Science and Engineering, vol. 63, pp. 95-114, 2019.

[15] J. Wang, Y. Guo, K. Zhang, G. Ren, and J. Ni, "Experimental investigation on hydraulic fractures in the layered shale formation," Geofluids, vol. 2019, Article ID 4621038, 14 pages, 2019.

[16] B. Harimi, M. Masihi, A. Mirzaei-Paiaman, and E. Hamidpour, "Experimental study of dynamic imbibition during water flooding of naturally fractured reservoirs," Journal of Petroleum Science and Engineering, vol. 174, pp. 1-13, 2019.

[17] J. Gong and W. R. Rossen, "Characteristic fracture spacing in primary and secondary recovery for naturally fractured reservoirs," Fuel, vol. 223, pp. 470-485, 2018.

[18] X. Zhou, Q. Yuan, Y. Zhang, H. Wang, F. Zeng, and L. Zhang, "Performance evaluation of $\mathrm{CO}_{2}$ flooding process in tight oil reservoir via experimental and numerical simulation studies," Fuel, vol. 236, pp. 730-746, 2019.

[19] Y. Tian, Y. Xiong, L. Wang et al., “A compositional model for gas injection IOR/EOR in tight oil reservoirs under coupled nanopore confinement and geomechanics effects," Journal of Natural Gas Science and Engineering, vol. 71, p. 102973, 2019.

[20] S. Al-Rbeawi, "Analysis of pressure behaviors and flow regimes of naturally and hydraulically fractured unconventional gas reservoirs using multi-linear flow regimes approach," Journal of Natural Gas Science and Engineering, vol. 45, pp. 637-658, 2017.

[21] S. Al-Rbeawi and D. Tiab, "Pressure behavior of partially penetrating multiple hydraulic fractures," Energy and Environment Research, vol. 2, no. 1, 2012.

[22] S. al Rbeawi and D. Tiab, "Impacts of reservoir boundaries and fracture dimensions on pressure behaviors and flow regimes of hydraulically fractured formations," Journal of Petroleum Exploration and Production Technology, vol. 4, no. 1, pp. 3757,2014

[23] P. Xie, Z. Gao, C. Li et al., "Conductivity of hydraulic fracturing in tight carbonate intra-platform shoal reservoirs," Journal of Petroleum Science and Engineering, vol. 189, p. 106976, 2020.

[24] J. Xu, B. Chen, B. Sun, and R. Jiang, "Flow behavior of hydraulic fractured tight formations considering pre-Darcy flow using EDFM,” Fuel, vol. 241, pp. 1145-1163, 2019.

[25] D. Denney, "Thirty years of gas shale fracturing: what have we learned?," Journal of Petroleum Technology, vol. 62, no. 11, pp. 88-90, 2015.

[26] R. Suarez-Rivera, L. Behrmann, S. Green et al., "Defining three regions of hydraulic fracture connectivity, in unconventional reservoirs, help designing completions with improved longterm productivity," in SPE 166505, In: SPE Annual Technical Conference and Exhibition, pp. 1-13, New Orleans, USA, September-October 2013.

[27] R. Jeffrey, A. Bunger, B. Lecampion et al., "Measuring hydraulic fracture growth in naturally fractured rock," in SPE 124919, In: SPE Annual Technical Conference and Exhibition, pp. 1-19, New Orleans, USA, October 2009.

[28] D. Chuprakov, O. Melchaeva, and R. Prioul, "Hydraulic fracture propagation across a weak discontinuity controlled by fluid injection," International Society for Rock Mechanics and Rock Engineering, Chapter, vol. 8, pp. 157-181, 2013.
[29] W. Wang, H. Peng, G. Li, L. Zhengdong, and L. Wenfeng, "Research on water flooding dynamic fractures to optimize infill drilling spacing in ultra-low permeability reservoirs, Changqing Oilfield," Petroleum Drilling Techniques, vol. 43, no. 1, pp. 106-110, 2015.

[30] J. Liu, Z. Xu, Z. Yuan, H. Bie, and P. Liu, "Numerical simulation study on fracture parameter optimization in developing low-permeability anisotropic reservoirs," Geofluids, vol. 2018, Article ID 1690102, 9 pages, 2018.

[31] Y. Lu, L. Zeng, Q. Xie, Y. Jin, M. M. Hossain, and A. Saeedi, "Analytical modelling of wettability alteration-induced micro-fractures during hydraulic fracturing in tight oil reservoirs," Fuel, vol. 249, pp. 434-440, 2019.

[32] W. Lu, Y. Wang, and X. Zhang, "Numerical simulation on the basic rules of multihole linear codirectional hydraulic fracturing," Geofluids, vol. 2020, Article ID 6497368, 14 pages, 2020.

[33] M. W. McClure, M. Babazadeh, S. Shiozawa, and J. Huang, "Fully coupled hydromechanical simulation of hydraulic fracturing in 3D discrete-fracture networks," SPE Journal, vol. 21, no. 4, pp. 1302-1320, 2016.

[34] R. Zhang, X. Zhang, T. Kang, and F. He, "Dynamic fracture propagation model for oriented perforation steering fracturing in low permeability reservoir based on microelement method," Journal of Natural Gas Science and Engineering, vol. 74, p. 103105, 2020.

[35] T. Fan, S. Wu, Q. Li, and B. Wang, "Low permeability reservoir numerical simulation by considering water-injection induced dynamic fractures," Special Oil \& Gas Reservoirs, vol. 42, no. 4, pp. 496-501, 2015.

[36] J. Xu, Y. Ding, L. Yang et al., "Effect of proppant deformation and embedment on fracture conductivity after fracturing fluid loss," Journal of Natural Gas Science and Engineering, vol. 71, p. 102986, 2019. 